\title{
Factors Influencing Students' Choice of Elective Science Courses: A Case Study from the American University of Sharjah
}

\author{
Fatin Samara \\ American University of Sharjah, Sharjah, United Arab Emirates \\ Email: fsamara@aus.edu
}

Received 29 July 2015; accepted 15 August 2015; published 18 August 2015

Copyright (C) 2015 by author and Scientific Research Publishing Inc.

This work is licensed under the Creative Commons Attribution International License (CC BY). http://creativecommons.org/licenses/by/4.0/

(c) (7) Open Access

\section{Abstract}

Scientific studies in higher education is becoming an increasing matter of discussion. The American University of Sharjah (AUS) encourages the scientific literacy of students who are not enrolled in science or engineering majors by including two required science courses in the curriculum. The courses of choice include biology, chemistry, environmental sciences, astronomy and physics. This study investigates the factors that contribute to students' choice when selecting science courses at AUS. A survey comprised of open-ended questions as well as quantitative enquiries was administered to students enrolled in environmental science (ENV 100), aiming to investigate the main reason behind their choice. The results of this two year study showed significantly positive attitudes toward the course contents and the benefit of the course towards their future careers. Furthermore, it reveals that students are highly influenced by previous experiences with subjects, professors' popularity, peer recommendation, their abilities in memorization, and skills in math. The study reveals that the main concern for students is related to the high amount of information and details that the course content covers. In addition, the possibility of obtaining a higher grade was also studied by observing the grade point average (GPA) for science courses over a period of four years. Nonetheless, the main factor for course choice was their genuine interest for the subject matter, which is this case study, was the environmental studies course.

\section{Keywords}

Environmental Sciences, General Education Courses, Course Choice, United Arab Emirates, Higher Education 


\section{Introduction}

Course choice among students in higher education represents an important decision and challenge. The two main aspects considered by students while making their choices typically include: course and grade satisfaction, and students' knowledge of their learning abilities [1].

In recent years, scientific advocacy groups have recognized the need for non-scientists to become scientifically literate. It is suggested that the knowledge of science will allow individuals to be able to make accurate observations and predictions, improves their ability to collect and organize data and make inferences. These are among the most basic of such skills acquired through basic scientific literacy [2]. Moreover, science courses serve as a unique forum to highlight the relationships between science, technology, and society [3]. Higher education institutions have the opportunity of increasing awareness, knowledge, skills, and values needed to create a just and sustainable future through educating its students in the sciences [4]. To enhance this idea, institutions such as the American University of Sharjah (AUS) have necessitated that students take at least two courses in the sciences including biology, chemistry, astronomy, physics and/or environmental sciences. AUS is located in United Arab Emirates (UAE) and it was founded in 1997 with the vision of becoming a leading educational institution in the Gulf region. AUS is currently the leading comprehensive coeducational and English instructing university in the Arab region, serving both local and international students, offering 26 majors and 54 minors at the undergraduate level, and 13 master's degree programs. Every year more than 1000 students enroll in a science elective course at the American University of Sharjah. The students enrolling in these courses are nonscience and non-engineering majors looking to complete a science elective requirement for their individual majors. Since these students are not enrolled in a science degree, the science course they choose marks the end of their formal education in science.

When it comes to students' choice, science elective courses are a great opportunity to increase and encourage the motivation of scientific inquiry among students who have chosen to avoid science courses throughout their academic life. On the other hand, this choice might not only involve the students' interest towards the subject but their perception towards the difficulty of the course. In addition, it is expected that students will be more inclined to choose courses that do not require too much effort or difficulty. Several studies have investigated student's perceptions of science courses. For example, Whitfield (1980) reported that the main reason for students' initial rejection of science courses is related to their perception of how difficult the course will be [5]. Several studies have supported this idea and concluded that students perceive sciences as a difficult subject, hence, affecting their course choice [6]-[9], in particular, has argued that the role of situational interest is highly significant in classrooms or subjects where children are disinterested in the subject at hand or are academically unmotivated. Moreover, many faculty members believe that students who enroll in science courses are learning to appreciate and grow enthusiasm for a new field, whereas students are too often struggling with unfamiliar vocabulary which sometimes results in a decreased level of understanding and interest of this science courses [10]-[12]. As teachers, we are convinced that students in science courses will be provided with a unique experience and knowledge opportunity, but students seem to have difficulty in grasping the knowledge.

To overcome students’ perceptions, De Boer (2000) investigated the goals of teaching science courses [13]. The goals were based on the application of science in relation to culture, future career goal, everyday life application, popular media influence, and keep updated with technological application, among others. These goals are all related to the life of individuals and might be potential reasons behind why students are more attracted to certain science courses over others, since they are influenced by the students' background, and future career plans.

The aim of this paper was to investigate students' choice towards the selection of a science course rather than other courses, and what are the factors influencing their decision (grades, difficulty, understanding of material, etc.). Moreover, this study uses the environmental sciences course (ENV 100) offered at the American University of Sharjah, as a case study due to its high demand among students. ENV 100: Principles of Environmental Science, at the American University of Sharjah (AUS), is a science elective course (amongst biology, chemistry, astronomy and physics) for students in general education who are not pursuing degrees in the sciences or engineering majors. ENV 100 introduces the basic principles of environmental science; it explores the scientific method, structure of matter, energy principles, ecological concepts, organism interactions, communities and ecosystems, population dynamics, energy sources, biodiversity, human activities and the environment, managed ecosystems, water management, air quality and solid waste management [14]. To our knowledge this is the first 
study that investigates the sciences course choice in higher education institutions in the United Arab Emirates.

\section{Method}

\subsection{Participants}

Participants included approximately 150 undergraduate students enrolled in ENV 100: Principles of Environmental Science, a course for non-science and non-engineering students at AUS through a period of four semesters (2012-2014). Sixty-four percent of those students were of Arab origin and thirty-six percent were non Arabs. In terms of gender, $67 \%$ of the surveyed students were females and $33 \%$ males. From the test group, the majority of students who completed the surveys were freshman (43\%), followed by sophomores (39\%), and only $18 \%$ were juniors or seniors. Course timings varied between the sections studied; three days a week for 50 minutes in the morning, afternoon, or twice a week for 75 minutes early morning. Students' majors of study included architecture, mass communication, business, and international studies.

\subsection{Data Collection}

Students were asked to complete a survey during the first month of classes. The questions were qualitative in nature and asked students to discuss their experiences with any previous courses taken at AUS, reasons for enrolling in the current course, they were also asked to provide feedback on their expectations for the course and/or the faculty teaching the course. Furthermore, a follow-up survey was given to the students taking ENV 100 during the last month of class. The questions included in the follow up survey were all based on their experience towards the current course and faculty. In the final survey, students were also asked whether or not they liked the course, how the course changed their attitudes towards the subject (environmental studies) and what their favorite part of the course was. Using the responses from the first semester's pilot study, a quantitative survey was developed to also include their perspectives before and after taking the course. This survey focused on comparing the five science elective courses offered at AUS which include: biology, chemistry, environmental sciences, astronomy and physics for non-scientist and non-engineering students. Students were asked to rate in order of interest these five courses in terms of their personal perception of difficulty, interest in the subject, and real life applicability of the material to be studied. The survey was completed anonymously and students were told that results would not have an impact on the student's grade and/or performance in the course. Students were allowed the choice to abandon the completion of the survey as it was done voluntarily.

\subsection{Average Grade Data}

Data on the average grades per science elective for non-science majors including chemistry, biology and environmental sciences were obtained and investigated regardless of the professor teaching the course. Data including fall, spring and summer semesters where used as a matter of comparison starting from fall 2009 until fall 2013 (data trends were used base on the last five years). The amount of sections offered per course during these four years was also quantified. Courses such as physics and astronomy were not compared in this section, as these courses do not belong to the Department of Biology, Chemistry and Environmental Sciences.

\section{Results and Findings}

\subsection{Initial Survey}

This survey was intended to assess the current status of students regarding their experiences with other courses taken at AUS and/or in the science field and expectations of how these courses can be improved. When given the chance to express their concerns prior to starting the course, students who enrolled in ENV 100 were mainly concerned about the amount of information to be studied and difficulty of course content and material. They also expressed a lack of interest towards science education in general but conceded that they had to earn credits for two science courses for graduation requirement.

In this initial survey, students were asked to rate from the list of science elective courses the ones that they would be more inclined to enroll in. Students were asked to rate from 1 to $5 ; 1$ being their preferred choice and 5 the course least likely to enroll in. This paper will present the percentages for 1 and 5 only for all the survey questions. Table 1 shows the students selection in order of most and least inclined. 
The results of this survey clearly show that students are more motivated to enroll in environmental sciences as their first choice. On the other hand, surveyed individuals believe that biology will be their last option for science requirements. Students' comments towards their decision on the above question included the math skills required for some courses, their high school science experience or lack thereof, ease of the subject matter, need for memorization of material and interest towards the subject. Also, some students commented on the idea that it is better to choose what they perceived would be an easier course for fear that a tougher course might lower their grade point average (GPA). The fact that most of the students having to enroll in this course did not have any previous science courses in high school also contributed to their course choice as biology and chemistry are perceived as hardcore science courses while the other courses seem to be more familiar and less demanding to them. The idea of enrolling in a new interesting course subject was also addressed by several individuals.

As a continuation of the previous question, students were required to explain the reason for their choice to enroll in the specific class and section (environmental sciences) rather than enrolling in one of the other available science electives. Table 2 shows a summary of the students' responses.

When analyzing the responses provided by the surveyed students, it is obvious to observe the fact that students are choosing the course available because it is a graduation requirement. Other factors that influenced their choice included their interest towards the subject, in this case, environment studies, as well as its applicability to real life events. Professors' popularity was also highlighted by several students as a reason for course choice. The last point is in agreement with Osborne, Simon \& Collins (2003), who suggested that the problem of negative attitudes towards school science could be obtained by focused studies of classrooms where effective teaching of science were utilized [15]. He argues that the teacher facilitating a course is a significant factor that can change students' attitudes towards a course, instead of the course itself. It is highly observed in this survey that students are highly influenced by their peers comments and recommendations when it comes to choosing the most suitable course.

Course difficulty was also examined in this paper. Students were requested to rate in order of difficulty the five elective science courses offered at AUS. The results of this survey indicated that students consider physics to be the most difficult course, followed by biology. In addition, environmental sciences were considered to be the least difficult amongst the choices provided. Surprisingly, although physics was chosen to be the most difficult one, it was also selected by several students as the least difficult after environmental sciences as shown in Table 3.

Other, comments obtained by the surveyed groups included the importance of classroom dynamics when taking a course. Most students agreed courses that involve interactive activities and class visuals enhanced their

Table 1. Course choice rating based on preference of enrollment.

\begin{tabular}{ccc}
\hline Science elective offerings & $\begin{array}{c}\text { Preferred choice } \\
\text { (\% of students) }\end{array}$ & $\begin{array}{c}\text { Not-preferred choice } \\
\text { (\% of students) }\end{array}$ \\
\hline Biology & 12 & 38 \\
Chemistry & 14 & 33 \\
Physics & 21 & 28 \\
Astronomy & 19 & 12 \\
Environmental sciences & 47 & 5 \\
\hline
\end{tabular}

Table 2. Reasons for course choice.

\begin{tabular}{cc}
\hline Factors for ENV 100 students & \% of student responses \\
\hline Science elective requirement & 45 \\
Interesting subject and applicability to future career & 35 \\
Professor popularity and peer recommendations & 28 \\
Easier and better course option & 6 \\
Timing of the course & 6 \\
\hline
\end{tabular}


learning abilities. Moreover, the idea of been able to apply the material learned to real life situations influences their course choice as well. According to several studies that investigated similar scenarios, students responded that they appreciated the applicability of the projects in courses to the real world and to their area of study [16]. In order to address these points, students were asked to rate the available science electives in order of what they perceived would be more applicable to real life or to their future careers. Table 4 shows that the highest percentage of students (74\%) believes that an environmental sciences course is the most applicable subject to real life, thus the reason they enrolled in the course. On the contrary, $43 \%$ of the students find astronomy to be a course that is the least applicable for everyday life situations. One of the reasons for their response might rely on the fact that several of these students are not sure what are actually offered in the astronomy course.

Finally, the surveyed groups were requested to make suggestions for improvement to all faculties teaching science courses including ENV 100. Students agreed that the instructor should motivate them to be more excited about the subject. They also believed that the use of real life examples and more visuals increase their learning and appreciation for the course. Students also suggested that the faculty teaching the science courses should include more in-class experiments, reduce course material and level of difficulty, and elucidate its content at a slower pace. Several surveyed students recommended that the final exam format be changed from a comprehensive final to a content specific exam. On the other hand, a high percentage of the students believe that no changes are necessary in the case study course or any other science courses offered at AUS.

\subsection{Final Survey}

The main goal of the follow-up survey was to have a better understanding of how students feel about their course choice in this case environmental sciences, towards the end of the semester. $91 \%$ of the students who completed the survey responded positively when asked if they enjoyed the course. On the other hand, $4 \%$ did not like the course and the other $4 \%$ were neutral about their interest or enthusiasm towards the course. When asked if they had other comments or recommendations to improve the course, $49 \%$ of the students suggested that the course and professor were great and no comments or advice were required. A total of $19 \%$ requested the instructor reduce the amount and specificity of the course material, length, and difficulty. Other comments were based on the class timing, final comprehensive exam and the addition of in-class experiments and videos. When asked if the course has changed their attitude towards the environment and its issues, $95 \%$ of the surveyed students answered affirmatively, suggesting that now they will be more careful and aware of their surroundings and contribute more towards a better and more sustainable environment.

Table 3. Course choice rating based on student's perception on subject difficulty.

\begin{tabular}{ccc}
\hline Science elective offerings & $\begin{array}{c}\text { Most difficult } \\
\text { (\% of students) }\end{array}$ & $\begin{array}{c}\text { Least difficult } \\
\text { (\% of students) }\end{array}$ \\
\hline Biology & 24 & 17 \\
Chemistry & 19 & 10 \\
Physics & 29 & 26 \\
Astronomy & 10 & 34 \\
Environmental sciences & 17 & 22 \\
\hline
\end{tabular}

Table 4. Course choice rating based on real life applicability.

\begin{tabular}{|c|c|c|}
\hline Science elective offerings & $\begin{array}{l}\text { Most applicable } \\
\text { (\% of students) }\end{array}$ & $\begin{array}{l}\text { Least applicable } \\
\text { (\% of students) }\end{array}$ \\
\hline Biology & 17 & 9 \\
\hline Chemistry & 5 & 29 \\
\hline Physics & 5 & 16 \\
\hline Astronomy & 7 & 43 \\
\hline Environmental sciences & 74 & 3 \\
\hline
\end{tabular}




\subsection{Average Grade Data}

To understand the concept of course difficulty in regards to student grades, GPA averages for all students enrolled in the science electives of biology, chemistry and environmental sciences during 2009-2013 time period were compared. Data obtained includes the fall, spring and summer semesters. Only average GPA's were taken into consideration regardless of faculty teaching the course. The following chart shows the differences per year between the 3 major courses. As seen in Figure 1, there is no significant difference between environmental sciences, biology and chemistry.

Finally, the number of course sections offered during the last 4 years was also compared showing that environmental science is indeed a very popular course with fifty sections offered during the four years, followed by biology with 45 sections opened and finally chemistry which included 29 general science elective sections. When looking at these grades and sections offered, we can refer to the studies by As Havard (1996); it previously explained that for a physics course, over $50 \%$ of his sample indicated that they did not enjoy the subject at all, or very little, whereas over $60 \%$ enjoyed biology a lot or quite a lot. Biology and environmental sciences are courses that students can readily relate to more since they discuss environmental issues as well as human systems, which is easier to understand for non-science students [7]. On the contrary, chemistry courses (as well as physics) include more problem solving and less real life examples (according to many students). Perhaps, courses such as chemistry and physics are considered to be more abstract including concepts that students do not relate to and cannot visualize; on the other hand, environmental science and biology courses include concepts that are more tangible and relatable to students. However the comparison of average GPA's does not entirely correlate with the student's responses about difficulty of the courses and preference on course enrollment. In general, the results of this research showed that the majority of students are not necessarily influenced by the ease of a course, but the idea of relating to the material has a greater impact. On the other hand, obtaining a higher grade in the course was considered an important factor of choice by several students. De Boer (2000) notes that "there is nothing wrong with teachers teaching as much scientific content as they wish to, as long as that content is meaningful and important to them and is taught in a way that students are able to comprehend and appreciate, not as lifeless abstractions” [13]. This article provides a key point in helping faculty realize that the main importance should not be given to the length of the material or even material content, but to the way that this material is taught and presented to the students to allow for a better understanding of those concepts. Courses, such as chemistry and biology are essential to the learning of science and perhaps these difficult subjects should be enhanced by using teaching methods that are less traditional.

\section{Conclusions and Future Study}

The purpose of this research was to investigate the factors that influence students' choice of science elective courses at AUS. The environmental Science course was used as a case study course for this investigation over a three year period. The results of this study showed that students course choice is based on; the content of the course, its relation to daily life and familiar events, grade of difficulty of the course, and to certain degree the

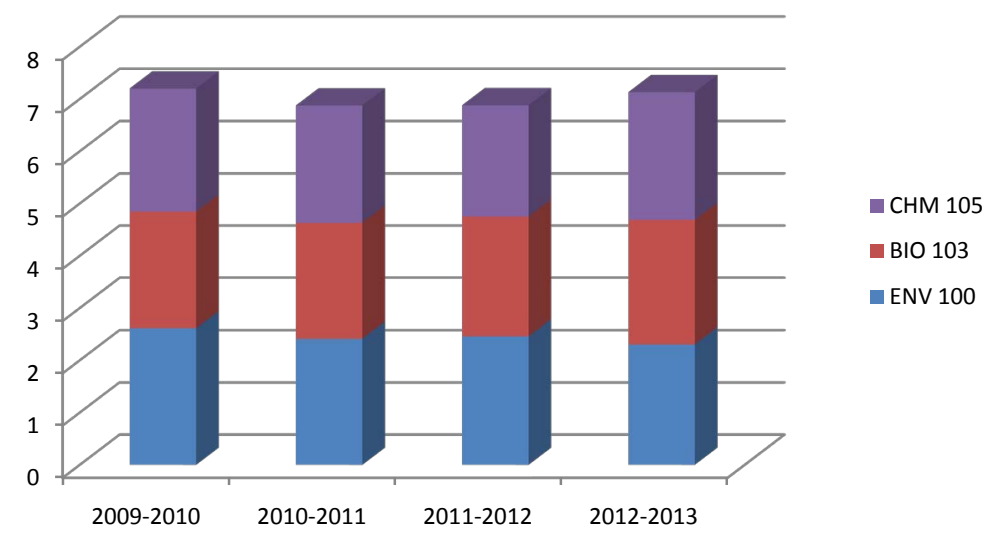

Figure 1. GPA average of students enrolled in general education science courses during 2009-2013 semesters. 
professor's popularity and finally recommendations from peer students. Science education has historically and traditionally involved students in proposing a hypothesis, conducting an investigation, answering a question, writing results, and stating a conclusion - whether the hypothesis was correct, incorrect, or undetermined. Environmental science courses have moved away from traditional teachings and currently involve more of an open discussion of current issues which students can relate to, especially those who are not pursuing a career in sciences. Large in-class discussions on global environmental issues provide students the opportunity to freely express their opinions in an academic setting. They expose themselves to varying opinions, thereby improving their critical thinking skills. Students who enrolled in the environmental science course reported that the course was highly applicable to real life and the concepts learned could be used in their future careers. For these reasons, students confirmed that the case study course (ENV 100) changed their perspective towards the environment and increased their awareness towards environmental issues, suggesting that all those are important factors considered by students looking to enroll in a science course.

\section{Acknowledgements}

The author of this paper would like to acknowledge Dr. Cindy Gunn, for her encouragement to perform this type of study and for all her useful comments in the writing of this paper. Thanks to Jenifah Abu-Hassan, Sana Sayed and Dina Fakoussa for their appreciated revisions to the paper. Finally, many thanks to the students taking environmental sciences during the fall, spring and summer semesters 2012-2014.

\section{References}

[1] Sabot, R. and Wakeman-Linn, J. (1991) Grade Inflation and Course Choice. The Journal of Economic Perspectives, 5 , 159-170. http://dx.doi.org/10.1257/jep.5.1.159

[2] Leonard, W.H. (2000) How Do College Students Best Learn Science? Journal of Collective Science Teaching, 29, 385388.

[3] Prather, E.E., Slater, T.F., Adams, J.P., Bailey, J.M., Jones, L.V. and Dostal, J.A. (2005) Research on a Lecture-Tutorial Approach to Teaching Introductory Astronomy for Non-Science Majors. The Astronomy Education, 2, 122-136.

[4] Cortese, D.A. (2003) The Critical Role of Higher Education in Creating a Sustainable Future. Planning for Higher Education, 31, 15-22.

[5] Whitfield, R.C. (1980) Educational Research \& Science Teaching. School Science Review, 60, 411-430.

[6] Crawley, F.E. and Black, C.B. (1992) Causal Modelling of Secondary Science Students intentions to Enroll in Physics. Journal of Research in Science Teaching, 29, 585-599. http://dx.doi.org/10.1002/tea.3660290607

[7] Havard, N. (1996) Student Attitudes to Studying A-Level Sciences. Public Understanding of Science, 5, 321-330. http://dx.doi.org/10.1088/0963-6625/5/4/002

[8] Hendley, D., Parkinson, J., Stables, A. and Tanner, H. (1995) Gender Differences in Pupil Attitudes to the National Curriculum Foundation Subjects of English, Mathematics. Educational studies, 21, 85-97. http://dx.doi.org/10.1080/0305569950210107

[9] Stables, A., Hendley, D. and Stables, S. (1996) Pupils’ Subject Preferences at Key Stage 3 in South Wales. Educational Studies, 22, 177-186. http://dx.doi.org/10.1080/0305569960220204

[10] Bailey, J.M., Jones, L.V. and Slater, T.F. (2003) How Astronomers View Their Role as Instructors. The 126th Meeting of the American Association of Physics Teachers, Austin.

[11] McDermott, L.C. and Redish, E.F. (1999) Resource Letter PER-1: Physics Education Research. American Journal of Physics, 67, 755. http://dx.doi.org/10.1119/1.19122

[12] Tobias, S. (1990) They're Not Dumb, They're Different: Stalking the Second Tier. Research Corporation, Tucson.

[13] DeBoer, G.E. (2000) Scientific Literacy: Another Look at Its Historical and Contemporary Meanings and Its Relationship to Science Education Reform. Journal of Research in Science Teaching, 37, 582-601. http://dx.doi.org/10.1002/1098-2736(200008)37:6<582::AID-TEA5>3.0.CO;2-L

[14] American University of Sharjah (2013-2014) Undergraduate Catalogue, Sharjah, 148.

[15] Osborne, J., Simon, S. and Collins, S. (2003) Attitudes towards Science: A Review of the Literature and Its Implications. International Journal of Science, 25, 1049-1079. http://dx.doi.org/10.1080/0950069032000032199

[16] Samaras, A.P., Howard, B.J. and Wende, C. (2000) Kyoto Redoux: Assessment of an Environmental Science Collaborative Learning Project for Undergraduate, Non-Science Majors. Canadian Journal of Environmental Education, 5, 26-47. 